\title{
Dinâmica espacial da indústria de embalagens plásticas no estado do Paraná
}

\author{
Silvia Cristina Limberger* \\ Fernando dos Santos Sampaio
}

\section{Resumo}

O presente trabalho analisa o desenvolvimento da indústria de embalagens no estado do Paraná. Buscamos descobrir como a indústria de embalagens plásticas se desenvolveu no Paraná, principalmente nas regiões com lento desenvolvimento industrial, que tem como característica a consolidação de setores tradicionais com menor grau tecnológico. Como elementos centrais para compreender a dinâmica do setor, estão o II Plano Nacional de Desenvolvimento (II PND), com a política de desenvolvimento industrial, principalmente de produtos de base e bens de capital, e o crescimento e diversificação do setor alimentício. Muitas indústrias de embalagens plásticas surgiram na década de 1990 em decorrência da reestruturação do setor alimentício que tornou a embalagem peça fundamental na comercialização do produto.

Palavras-chave: Indústria; Embalagens plásticas; Paraná; Setor alimentício.

\footnotetext{
Doutoranda pelo programa de Pós-Graduação da Universidade Federal de Santa Catarina (sillvgeo@yahoo.com.br).

*** Doutor em Geografia Humana pela Universidade de São Paulo - USP e professor do Curso de Geografia da Universidade Estadual do Oeste do Paraná - Campus Francisco Beltrão (fssampa@gmail.com),
}

Geosul, Florianópolis, v. 29, n. 57, p 177-195, jan./jun. 2014 
LIMBERGER, S.C. \& SAMPAIO, F.S. Dinâmica espacial da indústria de...

He spacial dynamic of plastic packaging plastic industry in the state of Parana

\begin{abstract}
This paper analyzes the development of plastic packaging industry in the state of Parana. We aim to find out how the plastic packaging industry has developed in state of Parana, mainly in regions with slow industrial development, which are characterized by the consolidation of traditional sectors with a lower degree of technological development. This paper takes as central aspects to understand the sector dynamics, the II Plano Nacional de Desenvolvimento (Second Nacional Plan of Development), with its industrial development policy, especially in commodities and capital goods, and the growth and diversification of the food industry. Many plastic packaging industries emerged in the 1990s a result of the restructuring of the food industry that turned the packaging the key player in the product marketing.

Key words: Industry; Plastic packaging; England; food industry.
\end{abstract}

\title{
Introdução
}

No Brasil o desenvolvimento da indústria de embalagens plásticas ocorreu a partir da política de substituição de importações na década de 1950, mas se consolidou somente na década de 1970 , com os investimentos do II PND. No Estado do Paraná o setor de embalagens plásticas foi impulsionado pelas políticas nacionais acompanhando as transformações da produção agrícola e o consequente desenvolvimento agroindustrial.

Na década de 1970 a economia brasileira encontrou acelerado crescimento industrial, e lento desenvolvimento tecnológico. A produção de plásticos foi impulsionada pelo Milagre Econômico e, principalmente, pelo II PND, com a política de substituição de importações, e abertura econômica para o exterior. Na década de 1980, conforme afirmam Castro e Souza (1985), o crescimento econômico se 
LIMBERGER, S.C. \& SAMPAIO, F.S. Dinâmica espacial da indústria de...

tornou negativo, mas a economia continuou a avançar, em decorrência do elevado nível de acumulação da década passada. As importações foram retraídas, alavancando a produção interna.

Durante as décadas de 1970 e 1980 o Paraná expandiu o setor agroindustrial e modernizou o setor de indústrias tradicionais como, da madeira, papel e alimentos. Segundo Padis (1981) a industrialização da agricultura ocorreu rapidamente devido aos créditos rurais e as políticas agrícolas lançadas pelo governo federal.

O II PND teve significativa importância no desenvolvimento industrial do estado do Paraná, pois buscava a expansão da capacidade produtiva de diversos ramos indústrias, principalmente de insumos básicos, por exemplo, a indústria química aumentou sua participação no valor adicionado das indústrias paranaenses de 12,72\% em 1975 para 25,07\% em 1985 (II PND, 1975).

O II PND formulou a política de desconcentração regional direcionando investimentos às regiões do Brasil com potencial industrial, porém pouco industrializadas. Desse modo passaram a se formar grandes complexos industriais e, principalmente, agroindustriais que modificaram e dinamizaram a economia do Estado.

Na década de 1990 novos investimentos foram destinados para as indústrias no Estado do Paraná. Consolidaram-se novos setores industriais, como o metal-mecânico, autopeças, eletrodomésticos, equipamentos agrícolas, laminados e artefatos de plástico e embalagens, além do fortalecimento do agronegócio.

A industrialização do Paraná foi conseqüência das políticas nacionais e também de políticas estaduais. Conforme IPARDES (2006) a criação do Banco de Desenvolvimento (BADEP), na década de 1960, tinha uma política de industrialização que se voltou basicamente para a construção de infraestrutura básica, que permitisse a integração da economia paranaense. Assim a atuação do BADEP foi importante apoio para o processo de industrialização do Estado do Paraná.

A indústria de embalagens plásticas está na categoria dos principais setores modernos inovativos do Estado do Paraná. O setor está concentrado na Região Metropolitana de Curitiba e Norte Central, 
LIMBERGER, S.C. \& SAMPAIO, F.S. Dinâmica espacial da indústria de...

porém muitas indústrias de embalagens vêm se desenvolvendo em outras regiões não características, como no Sudoeste, Oeste e CentroSul do Estado. Algumas indústrias do Estado são significativas nacional e internacionalmente, como a Dixie Toga, uma das principais indústrias de embalagens da América Latina, recentemente incorporada pela multinacional Bemis Company. Outras indústrias como a Incoplast, localizada em Marialva, a Implasul, em Pato Branco e a Zivalplast, em Quatro Barras, Região Metropolitana de Curitiba, têm importância nacional, abastecendo o mercado brasileiro e exportando em pequena quantidade.

Este trabalho consiste em um estudo de geografia econômica que tem como base de entendimento o método do materialismo histórico, o qual propõe uma investigação dos fenômenos econômico-sociais a partir da estrutura econômica da sociedade, pois é sobre esta base que se sustentam outros níveis da realidade: a superestrutura jurídico-política e ideológica.

\section{Estrutura produtiva industrial do Paraná e a inserção no mercado nacional}

O Estado do Paraná teve forte crescimento industrial na década de 1970, em decorrência das políticas de desenvolvimento industrial criadas pelo governo brasileiro. A política do II PND dinamizou a estrutura produtiva, principalmente nos setores de insumos básicos e de meios de produção, investimentos foram destinados ao desenvolvimento da produção em novas regiões até então pouco industrializadas.

Primeiramente a economia paranaense era voltada à produção da erva mate, produto que perdeu mercado devido à baixa qualidade e a concorrência de vários outros países. $\mathrm{Na}$ década de 1930, juntamente com a primeira etapa da industrialização brasileira, o Paraná expandiu suas lavouras de café, produto que sustentou a economia do estado até a década de 1970, e ainda continua sendo representativa. 
LIMBERGER, S.C. \& SAMPAIO, F.S. Dinâmica espacial da indústria de...

Durante as décadas de 1970 e 1980 o Paraná passou a expandir a agroindústria e modernizou a indústria tradicional, como madeira, papel e alimentos. A industrialização da agricultura ocorreu rapidamente, devido aos créditos rurais e as políticas agrícolas lançadas pelo Governo Federal (PADIS, 1981).

A industrialização do Paraná foi intensificada na década de 1970 com as políticas industriais do II PND. Firmou-se a política de desenvolvimento regional apontada anteriormente no Plano de Metas, as pequenas e médias empresas passaram a ter assistência através do CEBRAE - Centro Brasileiro de Assistência Gerencial à Pequena e Média Empresa, criado em 1972.

O II PND formulou a política de desconcentração industrial e desenvolvimento regional, incentivando as pequenas e médias empresas localizadas fora dos pólos produtivos do país e direcionando a essas regiões pouco industrializadas investimentos para os setores que precisavam ser ampliados naquele período, entre eles para os setores dependentes do petróleo. No estado do Paraná os setores com força regional passaram a receber incentivos do governo e foram ampliados e os setores não representativos passaram a ganhar força e ocupar posição na economia do Estado como o setor mecânico, metalúrgico e de materiais plásticos.

O Norte do Estado do Paraná foi beneficiado pela sua localização próxima à São Paulo, assim, muitas empresas expandiram sua produção ou instalaram seu parque produtivo nessa região. A cidade de Curitiba, primeira região industrializada no Estado, avançou seu desenvolvimento para a área metropolitana permitindo a construção de um importante pólo produtivo.

Houve intensa aglomeração da população na área urbana a partir da década de 1970, como efeito da implantação da alta tecnologia no meio rural. Essa mão de obra rural excedente se deslocou aos centros industriais em busca de trabalho, dando condições para o aumento dos lucros industriais, segundo Rangel (2005) o capitalismo implica na destruição da pequena produção, pois o monopólio vai ter maior capacidade de implantar tecnologia na propriedade extraindo um lucro muito maior. 
LIMBERGER, S.C. \& SAMPAIO, F.S. Dinâmica espacial da indústria de...

O Paraná passou a se integrar ao mercado nacional com as mudanças ocorridas na estrutura econômica na década de 1970. A partir desse período, o Estado passou a perder importância na produção dos gêneros tradicionais como produtos alimentares e madeiras, dando espaço para o surgimento de outros produtos caracterizados por maior grau de tecnologia, como a indústria química, que dobrou seu valor na participação do valor industrial agregado ao Estado. Essa reestruturação no parque industrial provocou a expansão das atividades que requerem alta tecnologia.

Segundo Relatório do Ipardes (2003), a estrutura produtiva do Estado do Paraná, na segunda metade da década de 1990, passou por uma reconfiguração através de duas bases dinâmicas. A primeira é a Região Metropolitana de Curitiba que dispõe de um recente parque industrial de unidades montadoras, incentivadas pelo governo do Estado. A segunda é a crescente expansão do agronegócio, caracterizado por pequenas e médias empresas locais. Neste setor, as grandes agroindústrias vêm contando com investimentos em modernizações.

A Região Metropolitana de Curitiba no ano de 1990 concentrou cerca de $90 \%$ do valor adicionado da indústria do Estado. A segunda metade da década marcou a desconcentração das unidades industriais, novas regiões passam a aumentar o número de estabelecimentos industriais, como a Região Centro-Oriental que aumentou sua participação no valor adicionado da indústria de 7,33\% em 1990, para 13,6\% em 2000 e a Região Sudoeste (não muito significativa) passa de 1,35\% em 1990, para 1,85\% em 2000. Algumas regiões não aumentaram sua participação, porque são vinculadas ao setor tradicional que não se modernizou ${ }^{1}$.

1 O Estado de Paraná possui indústrias em diferentes graus de industrialização. Segmentos tradicionais que não foram modernizados continuam a produzir e são segmentos importantes que tem grande participação no valor adicionado da indústria na região, como por exemplo, a região Londrina - Cambe no Norte Central do estado, possui no ano de $2000,28,65 \%$ do valor industrial adicionado no estado através de 
LIMBERGER, S.C. \& SAMPAIO, F.S. Dinâmica espacial da indústria de...

O setor de transformação de plástico está presente em seis das dez mesorregiões do Estado do Paraná que desenvolvem o setor de produtos modernos inovativos. Conforme dados do sistema FIEP - Federação das Indústrias do Estado do Paraná (2007) existem 74 indústrias de artefatos diversos de plástico no Paraná, com mais de 10 trabalhadores, e 25 com até 10 trabalhadores. Quanto as indústrias de embalagens, são 61 indústrias com mais de 10 trabalhadores e 20 indústrias com até 10 trabalhadores, distribuídas, principalmente, na Região Metropolitana de Curitiba e Norte Pioneiro do Estado (Londrina e Maringá).

\section{Surgimento e consolidação das indústrias de embalagens plásticas no Paraná}

Neste item apresentamos algumas características das indústrias de embalagens do Estado do Paraná e como tais indústrias estão inseridas no setor. Há um grande número de pequenas e médias empresas no setor, desse modo, no Estado do Paraná apenas uma indústria se constitui como líder, as outras são empresas que estão avançando tecnologicamente e se destacando na produção de alguns itens, porém, se encontram na mesma dimensão de milhares de indústrias de embalagens no Brasil. No Estado também verificamos a existência de muitas pequenas indústrias de embalagens com uma ou duas máquinas e poucos trabalhadores localizadas até mesmo em fundo de quintal terceirizando sua produção, esse processo foi identificado na Região Oeste do Estado, mas não analisado profundamente.

A indústria de embalagens plásticas possui alta composição orgânica do capital. A composição orgânica do capital se dá a partir de dois elementos, o capital constante e o capital variável. $\mathrm{O}$ capital constante se configura naquilo que é empregado na

segmentos não-especializados. Neste setor, se concentram principalmente as agroindústrias extensivas e extrativas mineral (IPARDES, 2003). 
LIMBERGER, S.C. \& SAMPAIO, F.S. Dinâmica espacial da indústria de...

produção. São os meios de produção onde ocorre a conservação do valor. Também é chamado de trabalho morto, pois materializa todo o trabalho necessário para a produção. Possui a aparência, uma máquina, por exemplo, mas para construí-la foi necessário o emprego de vários trabalhos humanos. $\mathrm{O}$ capital variável é onde ocorre a criação do valor. Também é chamado de trabalho vivo, pois é o próprio trabalhador, na aparência e na essência da produção, o único elemento capaz de produzir valor ${ }^{2}$.

No entanto, na indústria de embalagens plásticas o aumento da lucratividade se dá a partir da mais valia relativa, ou seja, da redução do tempo de trabalho proporcionada pelo aumento da tecnologia. $\mathrm{O}$ que nos interessa aqui é entender que o capitalista que emprega o modo de produção aperfeiçoado apropria-se do trabalho excedente, ou mais-valia relativa, em grau maior que aqueles que se apropriam os capitalistas do mesmo ramo. Porém, quando esse novo meio de produção é generalizado, desaparece a diferença da quantidade de trabalho utilizado para produzir determinada quantidade de mercadoria ${ }^{3}$.

Para elaboração do estudo buscamos analisar a lista de empresas de embalagens plásticas levantada pela Federação da Indústria do Estado do Paraná (FIEP, 2007) e os dados pertinentes a cada empresa foram buscados nos sites das empresas e relacionados.

${ }^{2} \mathrm{O}$ trabalhador possui um custo, que é o custo necessário a sua sobrevivência. $\mathrm{O}$ trabalho necessário para ele sobreviver. $\mathrm{O}$ custo da reprodução do trabalhador é apenas uma parcela $\mathrm{O}$ trabalhador consome o necessário para produzir, sendo assim, ele produz mais do que consome, gerando um excedente, trabalho excedente (horas trabalhadas além daquelas necessárias á sua sobrevivência e reprodução), consequentemente gerando a mais-valia. Por isso capital variável, pois o trabalhador é a única "ferramenta" capaz de produzir valor (MARX, 1985).

${ }^{3}$ Segundo Marx (1985) cada técnica, cada processo ou cada máquina que realiza o mesmo trabalho, com menor utilização de mão-de-obra, provoca em outros capitalistas a disputa para usar a mesma técnica, o mesmo processo ou a mesma máquina para inventar algo semelhante, a fim de que todos possam baratear suas mercadorias. 
LIMBERGER, S.C. \& SAMPAIO, F.S. Dinâmica espacial da indústria de...

Há 61 indústrias de embalagens com mais de 10 trabalhadores no Estado do Paraná, dessas selecionamos 37 que se enquadram principalmente no segmento de embalagens plásticas destinadas ao empacotamento de produtos alimentícios. Outras indústrias de embalagem de grande porte também foram consideradas. Das 37 empresas 3 foram fundadas na década de 1960, cinco na década de 1970, 7 na década de 1980, 14 na década de 1990 e 2 no primeiro qüinqüênio da década de 2000 .

A Dixie Toga foi criada em 1995, resultado da união de duas grandes empresas de embalagens: a Dixie Lalekla ${ }^{4}$ e a Toga. Tornou-se a maior fabricante de embalagens plásticas do Brasil e uma das maiores da América Latina. A empresa atende os mercados de alimentos, higiene pessoal e limpeza, bebidas, tabaco, farmacêutico e cosmético, e fornece para diversas empresas do Brasil e do exterior. Suas unidades se agrupam nas divisões de embalagens flexíveis, rígidas, descartáveis, cartuchos e rótulos.

Em 2005 a Dixie foi adquirida pela Bemis Company ${ }^{5}$, maior fabricante de embalagens flexíveis dos Estados Unidos, originando a Itap Bemis com altas tecnologias nas embalagens de snacks, frigorificados, higiene, desidratados e laticínios. Depois de ser adquirida construiu uma nova unidade em Rondonópolis no Estado do Mato Grosso, voltada à produção de embalagens encolhíveis para o segmento de frigorificados e laticínios e adquiriu as operações do Brasil e Argentina da Huhtamaki.

${ }^{4}$ A Dixie Lalekla, que deu início à sua história em 1946, era considerada uma das melhores do Brasil na produção de potes para margarinas, iogurtes e descartáveis e a Toga, fundada em 1935, uma das maiores fabricantes de embalagens flexíveis e semi-rígidas da América Latina.

${ }^{5}$ A Benis Company também incorporou em 2009 os negócios de plásticos rígidos da Huhtamaki, onde as vendas anuais do negócio vendido pela Huhtamaki giram em torno de 60 milhões de euros. Segundo ABIEF (2005) em 2005 a Amcor Flexibles, umas das empresas lideres mundiais em embalagens flexíveis e a ExxonMobil líder mundial em OPP, anunciaram parceria. 
LIMBERGER, S.C. \& SAMPAIO, F.S. Dinâmica espacial da indústria de...

A Dixie Toga possui algumas unidades industriais espalhadas pelo país (como se pode verificar no mapa a seguir) e três unidades na Argentina, uma unidade de embalagens flexíveis e duas de embalagens rígidas, a American Plast S.A. e a American Packaging, que detém $60,5 \%$ e $98,1 \%$ das ações, respectivamente. Além das unidades de embalagens plásticas, possui a Brasholanda, fábrica de máquinas para envase de produtos alimentícios como, iogurte, requeijão cremoso, creme, doce de leite, refresco, margarinas, água mineral sem gás e outros em copos/potes plásticos com fechamento através de tampa de alumínio termossoldável.

A Dixie Toga se tornou a mais importante empresa brasileira (até sua venda) no ramo de embalagens plásticas, atingindo economias de escala e escopo, adquiriu, associou-se e expandiu seu mercado. Segundo Chandler (1998) quando as indústrias atingiam um grau de investimentos em produção e distribuição suficiente para atingir as economias de escala e de escopo, passavam a incorporar novas unidades.

Novas unidades foram incorporadas de formas diferentes, juntando-se a outras empresas que utilizassem o mesmo processo para fabricação do mesmo produto e que almejavam o mesmo mercado (associação horizontal); incorporando unidades industriais que desempenhavam etapas anteriores ou posteriores na fabricação de um produto (integração vertical); expandindo-se geograficamente; e aproveitando o mercado que já dispunha para lançar novos produtos (CHANDLER, 1998).

A verticalização da empresa também ocorreu no setor de vendas, pois quanto mais as empresas diversificavam a produção, eram necessários mais cuidados especiais e conhecimento para vender tais produtos. A empresa intermediaria que desempenhava a função de venda precisava contratar novos trabalhadores, investir em instalações apropriadas reduzindo suas vantagens (CHANDLER,1998). Desse modo, as empresas em geral, possuem desenvolvido setor de vendas, pois além da comercialização ser 
LIMBERGER, S.C. \& SAMPAIO, F.S. Dinâmica espacial da indústria de...

controlada pela empresa, entregando o produto no prazo certo, é possível conhecer e analisar o mercado consumidor.

Contudo, sustento que, independentemente dos motivos da administração para investir em novas unidades, a grande empresa industrial raramente continuava crescendo ou mantinha-se competitiva por um período prolongado, a não ser que a incorporação de novas unidades (e, em menor medida, a eliminação de antigas) permitisse a hierarquia reduzir custos, aumentar a eficiência funcional na produção e também na comercialização e no aprovisionamento, aperfeiçoar produtos e processos para fazer face aos desafios e oportunidades decorrente da constante evolução da tecnologia e dos mercados (CHANDLER, 1998, p. 307).

Segundo dados divulgados pela Conjuntura Econômica (2007) a Dixie Toga é a segunda maior empresa brasileira de produtos plásticos ficando atrás somente da indústria Tigre de Santa Catarina. A terceira é a Cia Providência localizada na Região Metropolitana de Curitiba.

A Providência foi criada em 1963 na produção de embalagens plásticas voltadas ao setor alimentício, sua linha de produção foi sendo diversificada e centrou sua produção no segmento de não tecido de marca KAMI utilizado em diversos segmentos de mercado como, em fraldas descartáveis, roupas e artigos descartáveis de proteção médica e industrial, em aplicações em bens duráveis, coberturas agrícolas e embalagens diversas. A Companhia Providência é a empresa líder na fabricação e comercialização de não tecidos no Brasil com vendas internas, para América Latina e Estados Unidos.

O setor de produtos plásticos apresenta apenas três empresas como grandes do setor, a Tigre fabricante de produtos para a construção civil, a Dixie Toga fabricante de embalagens e a Cia Providencia líder na produção de não tecidos, assim a Dixie Toga tem a liderança na produção de embalagens plásticas no Brasil não encontrando qualquer concorrente. 
LIMBERGER, S.C. \& SAMPAIO, F.S. Dinâmica espacial da indústria de...

Além da Cia Providência a empresa Huhtamaki do Brasil Ltda foi criada na década de 1960. A Huhtamaki é atualmente uma das principais empresas de embalagens do mundo, fornece ao mercado embalagens de papel rígido, plástico, filmes, polpa moldada e máquinas.

Em São Paulo possui uma unidade In-house para a fabricação de embalagens injetadas, em Natal dedica-se à fabricação de laminados, chamada Laminor que é uma joint venture com a DixeToga (agora Bemis) e, no Recife possui uma unidade para a fabricação de embalagens injetadas. A empresa investiu em outras unidades de produção como a Dixie Toga e a Engepack.

Outras empresas criadas na década de 1960 foram a Plastimar, empresa de Origem portuguesa e atuante no Brasil. O Grupo Plastimar é líder em Portugal na produção de peças de poliestireno expandido para embalagem e construção, também produz produtos em polipropileno expandido, espuma composta de plástico, embalagens industriais, alimentares e peças técnicas para a indústria e lazer. Em 2008 a SYNBRA, com sede na Holanda, adquiriu a totalidade do capital social da empresa que passou a ser controlada pelo grupo Europeu. A indústria Procópio foi que em 2005 se tornou uma das maiores empresas do setor no país produzindo lonas, sacarias e insumos para big bags ${ }^{6}$.

Na década de 1970 com a política de industrialização brasileira e desconcentração industrial, foram criadas no Paraná novas indústrias de embalagem, entre elas a Inplasul, localizada no município de Pato Branco, que se tornou umas das maiores empresas do Estado. Em 2008 foi eleita uma das dez melhores empresas de flexografia do Brasil com o premio "Qualidade Flexo".

6 A sacaria é utilizada para envase de farinha, açúcar, sal, farelo, sementes, etc, e os sacos de big bag são utilizados pelas indústrias que necessitam de grande capacidade de estocagem, os sacos tem capacidade superior a 1 tonelada de produto envasado. 
LIMBERGER, S.C. \& SAMPAIO, F.S. Dinâmica espacial da indústria de...

A Inplasul é uma empresa familiar e está entre as 5 maiores indústrias de embalagens do Paraná, sua produção é de embalagens voltadas ao setor de alimentos, pet food e higiene com altos investimentos no setor de impressão. No ano de 2008 aumentou sua produção inserindo mais 100 trabalhadores na estrutura produtiva. A fábrica conta com uma ótima organização como o sistema kan ban e seus produtos são distribuídos em todo o Brasil (Trabalho de campo, 2007) ${ }^{7}$.

$\mathrm{Na}$ década de 1980 foram fundadas algumas indústrias de embalagem no Estado do Paraná, em decorrência do aumento da demanda de embalagens plásticas, e início do processo de produção de embalagens PET no Brasil. A Engepack, atualmente uma das maiores empresa do mercado brasileiro na produção de embalagens PET. É uma das principais fornecedoras de embalagens para o sistema coca-cola no Brasil. Em 1991 implantou no país o modelo europeu de operações de sopro "in house", ou seja, dentro da unidade do cliente.

A empresa busca se inserir em outros mercados, além do mercado de refrigerantes, como no mercado de cervejas e leites. É uma organização de capital nacional, tem como acionista majoritário a Pronor Petroquímica S/A que detém 78\% das ações e o Grupo Unigel, com 22\% das ações. A sede da Engepack está instalada na cidade de Simões Filho - na Região Metropolitana de Salvador (BA), e unidades de operação e distribuição localizadas nos Estados de São Paulo, Amazonas, Paraná, Ceará e Piauí.

Na década de 1970 e 1980, muitos países periféricos, na América do Sul principalmente no Brasil e na Argentina, surgiram

${ }^{7} \mathrm{Na}$ Região Sudoeste do Paraná tem destaque a indústria Incopal, não apontada pela FIEP (2007). A empresa foi criada em 1992 fabricando embalagens voltadas aos supermercados. Posteriormente, vendo o crescimento do mercado, foram fundadas mais duas empresas fabricante de embalagens para acondicionamento industrial e marcas. Seus clientes estão distribuídos por todo o Brasil e alguns países do Mercosul. 
LIMBERGER, S.C. \& SAMPAIO, F.S. Dinâmica espacial da indústria de...

fábricas modernas e intensivas em capital como indústrias petroquímicas, mecânicas e minérios. Esses países deram um salto na produção de tecnologia, porém, essa ainda era restrita comparada à tecnologia dos países centrais, pois se limitava ao aperfeiçoamento tecnológico secundário e investia-se pouco em pesquisa básica.

\section{Dinamização da indústria de embalagens plásticas voltadas para o setor alimentício}

O desenvolvimento do setor alimentício contribuiu para a expansão da indústria de embalagens plásticas, o qual incorporou novas tecnologias e diversificou sua linha de produtos, tornando a embalagem fundamental para a comercialização. A dinâmica da concorrência e a eliminação das indústrias de menor porte forçaram as indústrias alimentares a buscar novas estratégias para se manterem no mercado. A busca de inovações e a substituição de produtos tradicionais por uma gama de produtos altamente industrializados destinados ao consumo rápido dinamizou a indústria de embalagens.

Na década de 1990 temos o surgimento de muitas empresas de embalagens no Estado do Paraná, a maior parte delas voltadas para o setor alimentício. Dentre elas citamos a Zivalplast, produtora de sacolas plásticas para super mercados, a Deltaplam com embalagens especiais para o setor alimentício (barreiras a luz, gases, gorduras etc) e altos investimentos no setor de impressão; A Loydi Embalagens (Instituto Vicentino's do Brasil) que atende principalmente as indústrias lácteas de iogurtes e requeijão; A Plast \& Pack voltada para embalagens especiais para os produtos com alto grau de industrialização como requeijão, patê e inovações do setor alimentício; A Poly Plásticos é atuante na área alimentícia possuindo clientes com marcas líderes como a Mezzani, Avebon e a Coopavel e A Milplast fabricante de embalagens flexíveis, que já foi a principal fornecedora de embalagens do grupo Sadia. 
LIMBERGER, S.C. \& SAMPAIO, F.S. Dinâmica espacial da indústria de...

No quadro a seguir podemos observar as indústrias de embalagens atuantes no Paraná, destacando a Dixie Toga localizada no norte do estado e a Inplasul localizada no Sudoeste do estado.

\begin{tabular}{|c|l|l|l|}
\hline Empresa & \multicolumn{1}{|c|}{ Embalagens } & $\begin{array}{c}\text { Origem do } \\
\text { capital }\end{array}$ & \multicolumn{1}{c|}{$\begin{array}{c}\text { Capital } \\
\text { atual }\end{array}$} \\
\hline Deltaplam & Flexíveis & $*$ & $*$ \\
\hline Dixie Toga & Flexíveis, rígidas e descartáveis. & Nacional & $\begin{array}{l}\text { Bemis } \\
\text { Company }\end{array}$ \\
\hline Dyplast & Flexíveis & Nacional & Familiar \\
\hline Eliza & Horto fruticultura & Nacional & Familiar \\
\hline Engepack, & PET & Nacional & $*$ \\
\hline Implasul & Flexíveis & Nacional & Familiar \\
\hline Incoplast & Flexíveis & Nacional & $*$ \\
\hline Itap Bemis & Flexíveis & Norte americano & Bemis Company \\
\hline Loydi & Rígidas & Nacional & I. V. do Brasil \\
\hline Macroplastic & Sacolas para supermercados & Nacional & Familiar \\
\hline Milplast & Flexíveis e laminadas & $*$ & $*$ \\
\hline Parnaplast & Flexíveis & Nacional & Zemi \\
\hline Plast \& Pack & Rígidas & $*$ & $*$ \\
\hline Plastik & Horto fruticultura & Português & AD-REM \\
\hline Plastimar & Peças de poliestireno expandido & Português & SYNBRA \\
\hline Polisul & Horto fruticultura & Nacional & Familiar \\
\hline Procópio & Sacaria de ráfia (big bag) & $*$ & $*$ \\
\hline Zivalplast & Supermercados & Nacional & Familiar \\
\hline
\end{tabular}

Quadro 1: Indústrias do Paraná com a Produção de Embalagens Plásticas voltadas ao Setor de Alimentos

Fonte: Dados levantados em: sites das empresas, associações, sindicatos e trabalhos de campo. Organizado pela autora. * sem dados confiáveis.

Observamos que cerca de $60 \%$ das indústrias paranaense que produzem embalagens para o mercado de alimentos tem capital de origem nacional e familiar. Assim como aponta Mamigonian (2004) a 
LIMBERGER, S.C. \& SAMPAIO, F.S. Dinâmica espacial da indústria de...

maioria dos grandes grupos industriais nacionais surgiram de iniciativas modestas, pequenas indústrias de fundo de quintal, que encontraram um mercado promissor e se desenvolveram significativamente. A formação sócio-espacial é a base para compreender o processo produtivo de uma determinada região. Os imigrantes europeus que vieram para o Brasil tinham mentalidade empresarial para iniciar a produção industrial, transplantando a estrutura econômico-social de seus países de origem. Desse modo a cultura industrial brasileira está atrelada ao seu processo de colonização.

O surgimento das indústrias de embalagens plásticas nas Regiões Sudoeste, Oeste e Centro Sul do Estado do Paraná estão atreladas a esse processo de industrialização baseado na pequena produção mercantil. Essa produção mercantil tomou dimensões e avançou para o mercado nacional. As indústrias do Sul do Brasil aprimoravam-se constantemente, renovando máquinas e métodos de trabalho, pois tinham a desvantagem de estar longe dos principais mercados. Além disso, a ideologia do trabalho dos italianos e alemães foram passadas para as novas gerações.

Como aponta Mamigoniam (2004) as relações do centro do capitalismo nacional, São Paulo, com a Região Sul do Brasil não é uma relação centro-periferia, pois os estados do Sul possuem uma dinâmica própria de industrialização. Para ilustrar esse pensamento pode-se usar o fato da indústria Inplasul estar localizada na mesma cidade que a Sadia e possuir seus clientes em outras regiões do país.

\section{Considerações finais}

A industrialização brasileira surgiu a partir da produção de bens de consumo e não como a industrialização clássica, a partir dos meios de produção. Conforme Rangel (1986), nenhuma economia pode industrializar-se a partir da contração da capacidade de importar sem dispor de maquinaria para a produção interna. O II PND foi fundamental para esse processo, pois investiu na produção de bens de capital, tornando significativa a produção de maquinaria no Brasil. 
LIMBERGER, S.C. \& SAMPAIO, F.S. Dinâmica espacial da indústria de...

O setor de embalagens plásticas no Brasil teve um intenso crescimento nas últimas duas décadas, impulsionado pelo aumento da produção nacional de diversos setores que utilizam embalagens para manterem os produtos acondicionados e para agregar valor. $\mathrm{Na}$ primeira metade da década de 1990 ainda observamos o crescimento do número de empresas de plástico, mas, a partir segunda metade da década, há a redução, pois muitas pequenas e médias empresas não acompanham a competitividade do mercado, ocorre o fortalecimento de grupos nacionais e a entrada de grandes grupos multinacionais.

Em pesquisas realizadas descobrimos que o setor de embalagens das regiões não características como Sudoeste, Oeste e Centro Sul do Estado do Paraná possuem uma dinâmica própria, com mercados em todo o país e até mesmo no exterior, e que seu desenvolvimento está atrelado a reorganização do setor agroindustrial dessas regiões, porém, tais indústrias de embalagem criaram uma dinâmica própria e atualmente atendem todo o território nacional.

$\mathrm{O}$ fato das indústrias de embalagens plásticas terem se desenvolvido em regiões não características pode ser explicado por alguns fatores, pelas políticas de incentivo do II PND aos setores derivados de petróleo; o aumento dos produtos embalados em pequena quantidade com a expansão dos supermercados na década de 1980; em conseqüência da crise econômica e da decadência de muitas indústrias na década de 1990; e ainda pela expansão do setor de alimentos.

Segundo Mamigonian (2000) a periferia do sistema aumenta seu poder de industrialização nos momentos de recessão, quando o centro do sistema afetado pela crise diminui seu ritmo de produtividade em especial de produtos alimentares e matériasprimas, dando espaço à novos produtores. Ocorre à saída de capital dos centros dominantes que passam a investir em novas atividades, emergindo assim as indústrias originárias das pequenas cidades, agora com espaço considerável para concorrer. 
LIMBERGER, S.C. \& SAMPAIO, F.S. Dinâmica espacial da indústria de...

Desse modo o desenvolvimento das indústrias de plástico no Estado do Paraná teve início na década de 1970 e desde então vem tomando dimensão. Nos momentos de recessão necessita buscar novas estratégias de desenvolvimento.

\section{Referências bibliográficas}

ASSOCIAÇÃO BRASILEIRA DA INDÚSTRIA DE EMBALAGENS PLÁSTICAS FLEXÍVEIS (ABIEF). ABIEFFLEX, 2005, n¹8, janeiro-fevereiro. São Paulo: ABIEF, 2005.

\section{ASSOCIAÇÃO BRASILEIRA DA INDÚSTRIA DO PLÁSTICO (ABIPLAST).Perfil 2008. São Paulo, ABIPLAST, 2009.}

BRASIL. Lei $n^{\circ}$ 6.151, de 04 de dezembro de 1974. II PND Plano Nacional de Desenvolvimento. São Paulo: Sugestões Literárias, 1975.

CASTRO, Antonio Barros de, e SOUZA, Francisco Eduardo Pires de. A Economia Brasileira em Marcha Forçada. Rio de Janeiro: Paz e terra, 1985.

CHANDLER, Alfred. Ensaios para uma teoria histórica da grande empresa. Fundação Getulio Vargas, 1998.

CONJUNTURA ECONOMICA. 500 maiores S.A.. V. $61 \mathrm{n}^{\circ}$ 08, Fundação Getúlio Vargas, agosto de 2007.

DIXIE TOGA. Disponível em: em: <//www.dixietoga.com.br/ > Acesso em 14 de novembro de 2009.

FEDERAÇÃO DAS INDÚSTRIAS DO ESTADO DO PARANÁ FIEP. Cadastro das indústrias, fornecedores e serviços. 2007. 1 CD-ROM 
LIMBERGER, S.C. \& SAMPAIO, F.S. Dinâmica espacial da indústria de...

INSTITUTO PARANAENSE DE DESENVOLVIMENTO ECONÔMICO E SOCIAL (IPARDES). Paraná Economia e Sociedade. 2 ed. Curitiba: IPARDES/BRDE, 2006.

INSTITUTO PARANAENSE DE DESENVOLVIMENTO ECONÔMICO E SOCIAL (IPARDES). Leituras Regionais: Mesorregião Geográfica Sudoeste do Paranaense. Curitiba: IPARDES/BRDE, 2003.

MAMIGONIAN, Armen. Estudos de Geografia Econômica e de Pensamento Geográfico. Livre Docência: FFLCH-USP, 2004.

MAMIGONIAN, Armen. Teorias sobre a Industrialização Brasileira. Florianópolis: CFH/ UFSC, 2000.

MARX, Karl. O Capital: Crítica da Economia Política. 2 ed. São Paulo: Nova Cultural, 1985.

O PLÁSTICO DO BRASIL. Matérias-prima: o portfólio fica menos convencional. São Paulo: EXPORT PLASTIC, 2005. São Paulo, 2009. Disponível em: $<$ http://www.exportplastic.com.br/2009/> Acesso em 14 de março de 2009.

PADIS, Pedro Calil. Formação de uma Economia Periférica: o caso do Paraná. São Paulo: HUCITEC, 1981.

RANGEL, Ignácio. Economia: Milagre e Anti-Milagre. 2a ed. Rio de Janeiro: Jorge Zahar, 1986. 